\title{
Synthesis and performance of fluid loss agents based on different acrylamide monomers
}

\author{
Xinxin Liu • Pinhua Rao $\cdot$ Wenfa Xiao • \\ Qiang Xiao · Wenqi Zhang
}

Received: 26 October 2014 / Accepted: 2 February 2015/Published online: 13 February 2015

(C) The Author(s) 2015. This article is published with open access at Springerlink.com

\begin{abstract}
Acrylamide polymer, as one type of fluid loss agent (FLA), had attracted a strong interest in the applied petroleum research because of its outstanding characteristics of thickening and filtration control. The aim of this study was to synthesize a series of binary FLA using different acrylamide monomers and analyze the effect of monomer structure on the fluid loss control performance of FLA. Three kinds of FLA with the monomer of 2-acrylamido-2-methyl propane sulfonic acid (AMPS) were prepared by polymerization of AMPS with acrylamide (AM), $N, N$-dimethyl acrylamide (DMAM), N,N-diethyl acrylamide (DEAM), respectively, and characterized by FTIR, ${ }^{1} \mathrm{H}-\mathrm{NMR}$ and ${ }^{13} \mathrm{C}-\mathrm{NMR}$. The results showed that the FLA prepared by AMPS and DMAM (coded as ADM) showed the best water-retaining capacity, which can be attributed to its moderate rigidity group of $-\mathrm{CH}_{3}$. It was also revealed that the tolerance of cement slurry containing ADM to $\mathrm{Ca}^{2+}$ was stronger than that to $\mathrm{Mg}^{2+}$ and $\mathrm{Na}^{+}$.
\end{abstract}

Keywords Bipolymer - Fluid loss performance .

Acrylamide monomers $\cdot$ Structure effect

\section{Introduction}

In the field of oil drilling, cement slurry is usually used to reinforce the well wall to provide a stable and safe wellbore (Kelessidis et al. 2009; Kosynkin et al. 2012). To meet the requirements of cementing job, additives such as fluid loss agent (FLA) are used to improve performance of the

X. Liu · P. Rao $(\bowtie) \cdot$ W. Xiao · Q. Xiao - W. Zhang

School of Chemistry and Chemical Engineering, Shanghai University of Engineering Science, Shanghai 201620, China e-mail: raopinhua@hotmail.com cement slurry (Dugonjić-Bilić et al. 2011). FLA can control the loss of water from the cement slurry to porous formations and thus prevent the cement slurry from dehydrating. During the past few decades, various FLA including inorganic granular materials, modified natural polymers and synthetic polymers have been developed (Amani et al. 2012). Among them, synthetic polymers were widely studied due to satisfactory performance under complicated formation environment.

2-Acrylamido-2-methyl-propane sulfonic acid (AMPS) with a vinyl group is commonly used as monomer of synthetic FLA due to good thermal stability and low sensitivity to cations (Plank et al. 2006, 2010; Ma et al. 2014). Related researchers developed a series of FLA by copolymerization of AMPS with other monomers to control fluid loss of cement slurry (Peng et al. 2010). It was reported that the copolymer consisting of AMPS and acrylamide (AM) (coded as AAM) had a good performance reducing the fluid loss in oil well cementing (Tao et al. 2011). To further improve the performance of FLA, $N, N$ dimethyl acrylamide (DMAM) was used instead of AM to copolymerize with AMPS, and the copolymer synthesized (coded as ADM) was found to have a stronger temperature tolerance, resulting from reinforcement of molecular rigidity due to the existence of $-\mathrm{CH}_{3}$ (Guo et al. 2012). However, a more detailed study about performance of ADM was still needed under complicated formation environment. $N, N$-Diethyl acrylamide (DEAM) as homolog of DMAM has longer carbochain and thus, stronger rigid structure, which gives rise to a supposition that the copolymer consisting of DEAM and AMPS (coded as ADE) could possess better fluid loss control performance.

In this study, three kinds of FLA with similar structure, i.e., AAM, ADM and ADE, were synthesized by the method of aqueous solution polymerization and 
characterized with fourier transform infrared spectroscopy (FTIR) and nuclear magnetic resonance (NMR). Fluid loss control performance of three kinds of FLA was compared and detailed mechanisms were elucidated.

\section{Experimental section}

Materials

AMPS, AM, DMAM, DEAM, $\mathrm{NaCl}, \mathrm{MgCl}_{2}, \mathrm{CaCl}_{2}$, $\mathrm{NaHSO}_{3}$, $\left(\mathrm{NH}_{4}\right)_{2} \mathrm{~S}_{2} \mathrm{O}_{8}$ and $\mathrm{Ca}(\mathrm{OH})_{2}$ were of analytical grade and purchased from Sinopharm Chemical Reagent Co, Ltd. Liquid cement retarder additive (Diacel ${ }^{\circledR}$ HTR 100) was provided by Chevron Phillips Chemical Company.

Synthesis of bipolymer FLA

The FLA consisting of AMPS and AM was prepared by redox free-radical polymerization in a four-necked flask. $35 \mathrm{~g}$ of AMPS was dissolved in $300 \mathrm{ml}$ of saturated solution of $\mathrm{Ca}(\mathrm{OH})_{2}$ with stirring at $25 \pm 2{ }^{\circ} \mathrm{C}$. $\mathrm{Ca}^{2+}$ was introduced in the polymer to increase the molecular weight of FLA through crosslinking role. After all AMPS was dissolved completely, saturated solution of $\mathrm{Ca}(\mathrm{OH})_{2}$ was further added into the solution slowly until $\mathrm{pH}$ of the solution reached to $10-10.5$. Then, $12 \mathrm{~g}$ of AM was put into the solution and stirred for 10 min under $\mathrm{N}_{2}$ atmosphere at $60{ }^{\circ} \mathrm{C}$. The reductant $\left(\mathrm{NaHSO}_{3}, 0.05 \mathrm{~g} / \mathrm{ml}\right.$, $0.9 \mathrm{ml}$ ) was dropped into the solution and stirred for $2 \mathrm{~min}$, and then the oxidant $\left[\left(\mathrm{NH}_{4}\right)_{2} \mathrm{~S}_{2} \mathrm{O}_{8}, 0.1 \mathrm{~g} / \mathrm{ml}\right.$, $1.6 \mathrm{ml}$ ] was added slowly and stirred for $20 \mathrm{~min}$. The addition of reductant and oxidant was repeated successively until viscous product was obtained. After the reaction was continued for $1 \mathrm{~h}$, the product was washed with $300 \mathrm{ml}$ of ethanol three times, separated by filter and dried under vacuum at $60{ }^{\circ} \mathrm{C}$ for $24 \mathrm{~h}$. The resulting product (i.e., AAM) was ground into fine powder and stored for use. ADM and ADE were synthesized using a similar method, respectively. The synthesis scheme of FLA is shown in Fig. 1.

\section{Characterization of FLA}

FTIR (Nicolet AVATAR380, USA) was employed to analyze the surface functional groups of FLA. KBr powder was used for sample preparation. ${ }^{1} \mathrm{H}-\mathrm{NMR}$ and ${ }^{13} \mathrm{C}-\mathrm{NMR}$ spectra of FLA were obtained by NMR instrument (Bruker Avance III $400 \mathrm{MHz}$, Germany), and $\mathrm{D}_{2} \mathrm{O}$ was used as solvent. TGA analysis with a $10 \mathrm{~K} / \mathrm{min}$ heating rate under nitrogen (Linseis STA PT1000, Germany) was conducted to determine thermal degradation process of FLA.

Cement slurry preparation and fluid loss performance analyses

Cement slurry was prepared according to the API Specification using API Class G, for oil well cement and deionized water. First, FLA was dissolved in deionized water or saline water with different electrolytes (e.g., $\mathrm{NaCl}, \mathrm{MgCl}_{2}, \mathrm{CaCl}_{2}$ ), and then cement was added within $15 \mathrm{~s}$. A blade-type laboratory blender manufactured by Waring Products Inc. was used to homogenize the mixture for $35 \mathrm{~s}$ at 12,000 rpm. Water-to-cement $(\mathrm{w} / \mathrm{c})$ ratio is 0.52 . Admixture dosages were stated in $\%$ by weight of cement (bwoc). To ensure homogeneous consistency, cement slurry was stirred in an atmospheric consistometer at $27{ }^{\circ} \mathrm{C}$ for $20 \mathrm{~min}$.

Static fluid loss of cement slurry was determined following API RP 10B procedure and measured with a high temperature and high pressure (HTHP) filtration device (Fann HTD7169, USA). The fluid volume collected within 30 min was doubled as described by API RP 10B and regarded as API fluid loss of the corresponding cement slurry. Rheological properties of the cement slurry were evaluated by the viscometer (Fann 35SA, USA).

Thickening time of cement slurry was measured under atmospheric pressure using a consistometer (Fann model 275, USA). The cement slurry was poured into the HTHP consistometer cell and the time to reach $70 \mathrm{Bc}$ (Bearden unit of consistency) was sufficient to make the cement slurry unpumpable and was designated as thickening time of the cement slurry. All the experiments were run in triplicate.

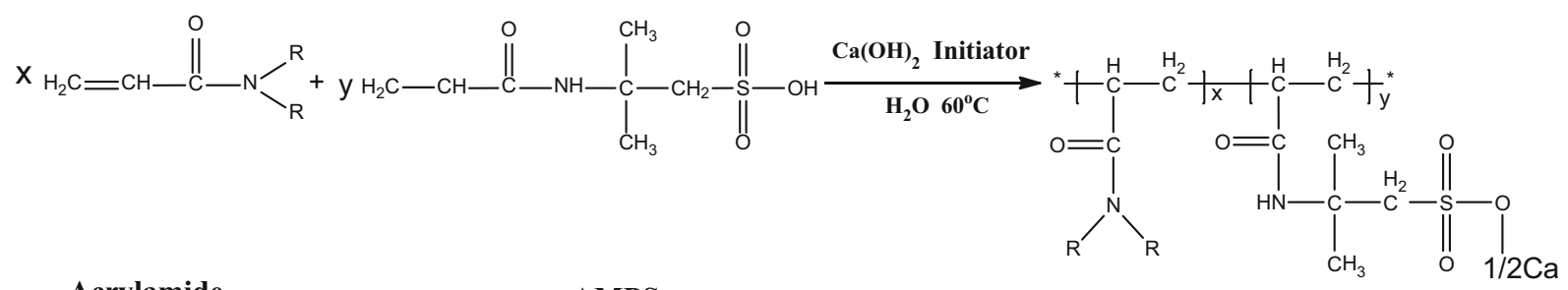

Acrylamide

AMPS

Bipolymer FLA

Fig. 1 Synthesis scheme of fluid loss additive (FLA) 


\section{Results and discussion}

\section{Characterization of FLA}

FTIR spectrum of AAM is shown in Fig. 2. The absorption peak at $3,421 \mathrm{~cm}^{-1}$ was attributed to the stretching vibration of $\mathrm{N}-\mathrm{H}$ in $\mathrm{AAM}$, which was echoed by bending vibration peak of $\mathrm{N}-\mathrm{H}$ occurring at $1,551 \mathrm{~cm}^{-1}$. The peaks at 2,979, 2,937 and $626 \mathrm{~cm}^{-1}$ were assigned to the stretching vibration of $-\mathrm{CH}_{3},-\mathrm{CH}_{2}$ and $\mathrm{C}-\mathrm{S}$ of AAM (Guo et al. 2013; Yan et al. 2013), respectively. The stretching vibration peak of $\mathrm{C}=\mathrm{O}$ in $\mathrm{AAM}$ was shown at $1,651 \mathrm{~cm}^{-1}$. Moreover, the peaks at $1185 \mathrm{~cm}^{-1}$ and $1,040 \mathrm{~cm}^{-1}$ should belong to $-\mathrm{SO}_{3} \mathrm{H}$ group of AAM (Zou et al. 2012; Varaprasad et al. 2010). Comparing with the FTIR spectrum of the monomer AMPS, the characteristic absorption peaks of $\mathrm{C}=\mathrm{C}$ at 1620 and $944 \mathrm{~cm}^{-1}$ disappeared in the FTIR spectrum of AAM, which demonstrated that $\mathrm{C}=\mathrm{C}$ bonds of AMPS and AM were opened and the target product AAM was formed. Similarly, the FTIR spectra of ADM and ADE in Fig. 2 also showed that the target product was synthesized by the expected monomers.

${ }^{1} \mathrm{H}-\mathrm{NMR}\left(\mathrm{D}_{2} \mathrm{O}\right)$ and ${ }^{13} \mathrm{C}-\mathrm{NMR}\left(\mathrm{D}_{2} \mathrm{O}\right)$ spectra of three kinds of FLA are shown in Fig. 3. Detailed spectral analyses based on Fig. 3 are summarized in Table 1. According to Fig. 3a, ${ }^{1} \mathrm{H}-\mathrm{NMR}$ peaks of olefinic bond in AMPS and AM, which should occur around 5.7-6.6 ppm, were not found, suggesting that polymerization had been carried out successfully. Similarly, ${ }^{1} \mathrm{H}-\mathrm{NMR}$ peaks (around 5.7-6.6 ppm) of olefinic bond in DMAM and DEAM also disappeared, which indicated that DMAM and DEAM successfully polymerized with AMPS, respectively.

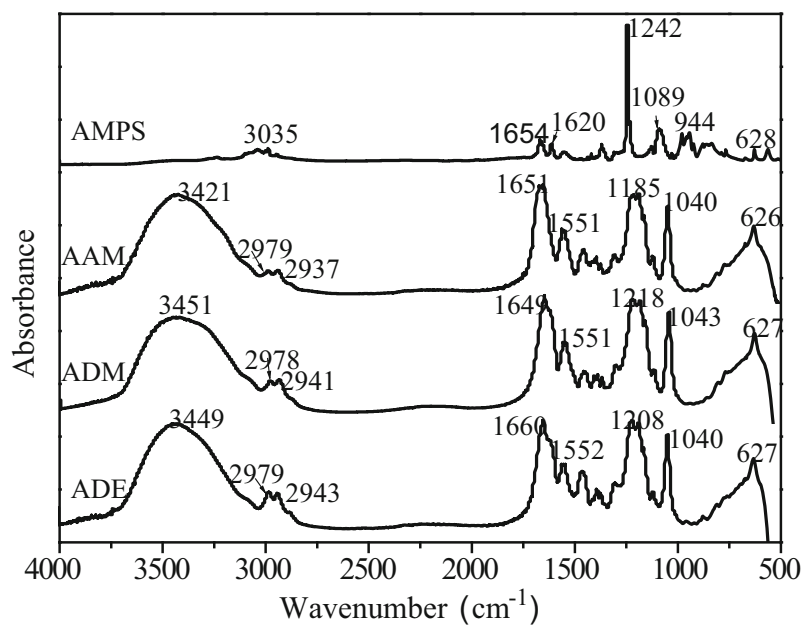

Fig. 2 FTIR spectra of FLA
Fluid loss control performance of FLA

The performance of various FLA reported in literatures was evaluated at respective experimental conditions, and the lack of comparability causes a need for assessing the performance of various FLA at same conditions. In this study, three kinds of FLA with similar structure, i.e., AAM, $\mathrm{ADM}$ and $\mathrm{ADE}$, were selected and fluid loss control performance of FLA was compared under $52{ }^{\circ} \mathrm{C}$. The results are listed in Table 2.

As indicated in Table 2, the shear stress in cement slurry increased with increase in the shear rate. ADM had the best fluid loss control performance among the three kinds of FLA. According to the static filtration equation:

$V_{t}=A(2 K \Delta p / \mu R)^{1 / 2} t^{1 / 2}$

where $V_{t}$ is the filtrate volume, $A$ is filtration area, $K$ is filter cake permeability, $\Delta p$ is static pressure difference, $R$ is reduced filter cake volume, $t$ is filtration time and $\mu$ is the dynamic viscosity (Plank et al. 2006; Clark 2010).

It could be seen that filtrate volume $V_{t}$, i.e., the fluid loss, is inversely proportional to viscosity $\mu^{1 / 2}$ of the cement slurry. Viscosity $\mu$, is reflected by shear stress as shown in Table 2 (Plank et al. 2010), which is related to the molecular weight and structure of FLA. As mentioned previously, AAM was prepared by polymerization of AM and AMPS. AM has $\mathrm{NH}_{2}$ group with two active hydrogen atoms, which was prone to be initiated by the initiator and produce more copolymer active centers, possibly leading to excessively vigorous reaction and thus lower degree of polymerization (Ma et al. 2014). In contrast, DMAM containing two methyl groups could produce relatively few active centers during polymerization, resulting in higher degree of polymerization and viscosity of ADM. Besides, two methyl groups of DMAM enhanced the hydrophobic association ability of ADM, which improved the blockage effect of cement slurry and thus, decreased fluid loss (Plank et al. 2006; Guo et al. 2012). For ADE, ethyl groups of DEAM could increase steric hindrance, resulting in decrease of degree of polymerization and viscosity of ADE.

Effects of temperature, dosage and salt on ADM performance

Figure 4 shows the effects of temperature on shear stress and fluid loss of cement slurry containing an ADM dosage of $0.8 \%$ bwoc. As observed, ADM on the whole had an excellent fluid loss control performance. With increase in temperature, the fluid loss of cement slurry increased, resulting from the decrease of viscosity of cement slurry as indicated due to change in shear stress. Fluid loss of cement slurry was about $42 \mathrm{ml}$ at $77^{\circ} \mathrm{C}$, indicating a stronger

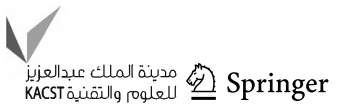




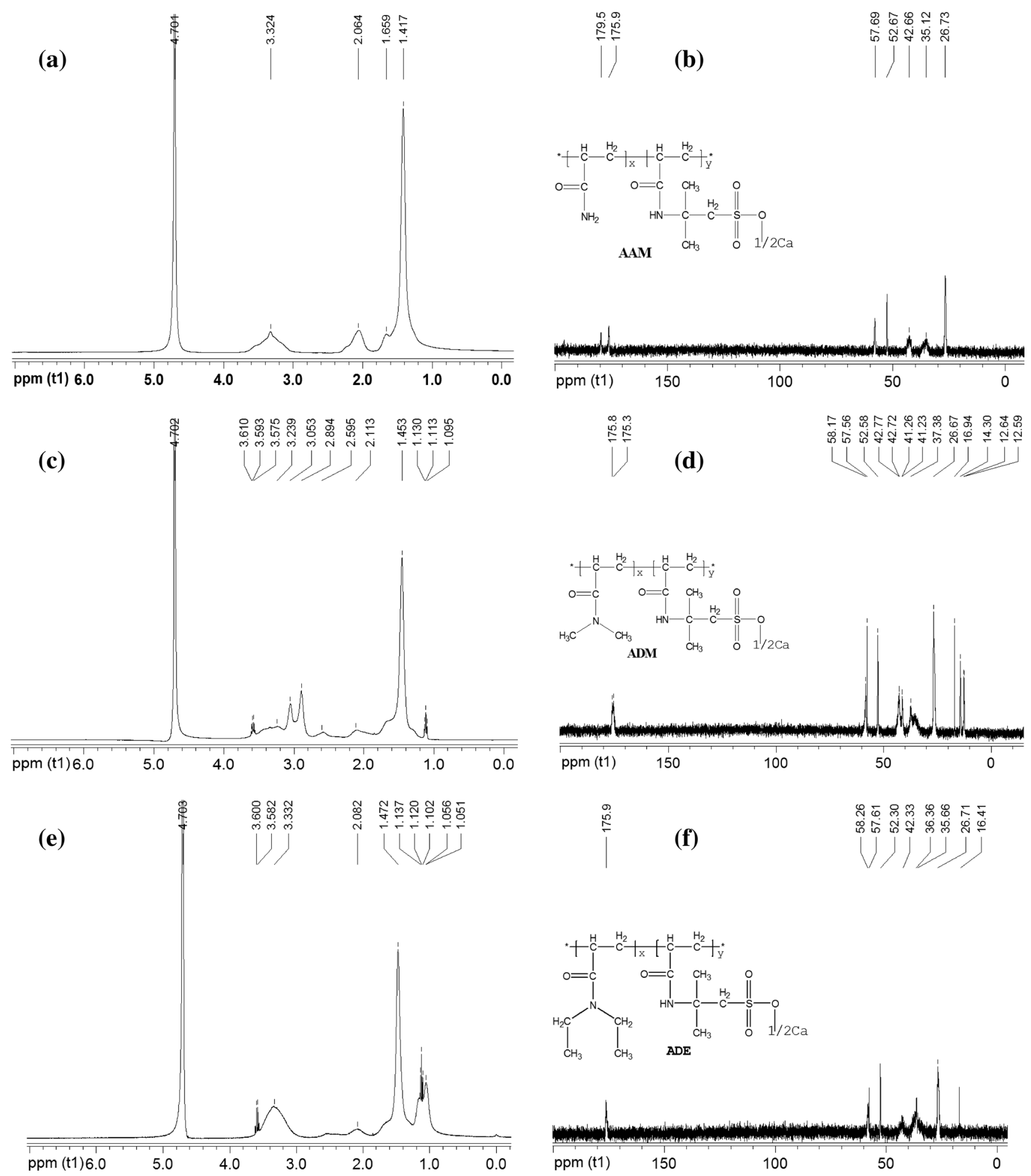

Fig. $3{ }^{1} \mathrm{H}-\mathrm{NMR}$ and ${ }^{13} \mathrm{C}-\mathrm{NMR}$ spectra of $\mathrm{AAM}(\mathbf{a}, \mathbf{b}), \mathrm{ADM}(\mathbf{c}, \mathbf{d})$ and $\mathrm{ADE}(\mathbf{e}, \mathbf{f})$

temperature tolerance of $\mathrm{ADM}$ and resulting from stronger rigidity of $\mathrm{ADM}$ molecule due to the existence of $\mathrm{CH}_{3}$.TGA spectrum of ADM echoed the results shown in Fig. 4. As observed in Fig. 5, ADM only had a little mass loss before $319^{\circ} \mathrm{C}$, resulting from the volatilization of free water. When the temperature was higher than $319^{\circ} \mathrm{C}$, apparent mass loss began to occur, resulting from the degradation of ADM backbone. The fastest mass loss temperature was $336^{\circ} \mathrm{C}$, confirming a high heat-resistance ability of ADM. 
Table 1 NMR spectra analyses summary of FLA

\begin{tabular}{|c|c|c|}
\hline FLA & NMR & Spectra analyses \\
\hline \multirow[t]{2}{*}{ AAM } & $\begin{array}{l}{ }^{1} \mathrm{H}- \\
\mathrm{NMR}\end{array}$ & $\begin{array}{l}1.42 \mathrm{ppm}, \mathrm{CH}_{3} \text { of AMPS; near } 1.66 \text { and } 2.06 \mathrm{ppm}, \mathrm{CH}_{2} \text { and } \mathrm{CH} \text { of the backbone of AAM, respectively; } 3.33 \mathrm{ppm}, \mathrm{C}-\mathrm{CH}_{2}-\mathrm{S} \text { in } \\
\text { AAM; } 4.70 \mathrm{ppm}, \mathrm{D}_{2} \mathrm{O}\end{array}$ \\
\hline & $\begin{array}{l}{ }^{13} \mathrm{C}- \\
\mathrm{NMR}\end{array}$ & 175.9 and $179.5 \mathrm{ppm}, \mathrm{C}=\mathrm{O}$ in AMPS and AM, respectively \\
\hline \multirow[t]{2}{*}{$\mathrm{ADM}$} & $\begin{array}{l}{ }^{1} \mathrm{H}- \\
\mathrm{NMR}\end{array}$ & $\begin{array}{l}1.1-1.13 \mathrm{ppm}, \mathrm{CH}_{2} \text { in the backbone of } \mathrm{ADM} ; 1.45 \text { and } 3.61 \mathrm{ppm}, \mathrm{CH}_{3} \text { and } \mathrm{C}_{-}-\mathrm{CH}_{2}-\mathrm{S} \text { of AMPS, respectively; near } 2.11 \text { and } \\
2.59 \mathrm{ppm}, \mathrm{CH}_{2} \text { and } \mathrm{CH} \text { in the backbone of } \mathrm{ADM} \text {, respectively; } 2.89 \mathrm{ppm}, \mathrm{CH}_{3} \text { of DMAM }\end{array}$ \\
\hline & $\begin{array}{l}{ }^{13} \mathrm{C}- \\
\mathrm{NMR}\end{array}$ & $\begin{array}{l}\text { 12.59-16.94 ppm, carbon backbone in ADM; } 26.67 \text { and } 37.38 \mathrm{ppm}, \mathrm{CH}_{3} \text { of AMPS and DMAM, respectively; } 175.3 \text { and } \\
175.8 \mathrm{ppm}, \mathrm{C}=\mathrm{O} \text { of AMPS and DMAM, respectively }\end{array}$ \\
\hline \multirow[t]{2}{*}{$\mathrm{ADE}$} & $\begin{array}{l}{ }^{1} \mathrm{H}- \\
\mathrm{NMR}\end{array}$ & $\begin{array}{l}1.05 \mathrm{ppm}-1.14 \mathrm{ppm}, \mathrm{CH}_{2} \text { in the backbone of DEAM; near } 1.14 \mathrm{ppm}, \mathrm{CH}_{3} \text { in DEAM; near } 1.47 \mathrm{ppm}, \mathrm{CH}_{3}-\mathrm{C}_{-} \mathrm{CH}_{3} \text { of AMPS; } \\
\text { near } 3.33 \mathrm{ppm}, \mathrm{CH}_{2} \text { of ethyl groups; } 3.6 \mathrm{ppm}, \mathrm{C}-\mathrm{CH}_{2}-\mathrm{S} \text { of AMPS. }\end{array}$ \\
\hline & $\begin{array}{l}{ }^{13} \mathrm{C}- \\
\mathrm{NMR}\end{array}$ & $\begin{array}{l}\text { Near } 16.41 \text { and } 36.36 \mathrm{ppm}, \mathrm{CH}_{3} \text { and } \mathrm{CH}_{2} \text { of DEAM, respectively; } 26.71 \text { and } 35.66 \mathrm{ppm}, \mathrm{CH}_{3} \text { and } \mathrm{CH}_{2}-\mathrm{S} \text { in AMPS, } \\
\text { respectively; near } 175.9 \mathrm{ppm}, \mathrm{C}=\mathrm{O} \text { in AMPS and DEAM }\end{array}$ \\
\hline
\end{tabular}

Table 2 Rheological properties and fluid loss of cement slurry containing FLA (bwoc, $0.8 \%$ ) at $52{ }^{\circ} \mathrm{C}$

\begin{tabular}{llllllllll}
\hline FLA & \multicolumn{3}{l}{ Shear stress $\left(\mathrm{lbs} / 100 \mathrm{ft}^{2}\right)$} & at different shear rates $(\mathrm{rpm})$ & & Thickening time (min) & API fluid loss (ml) \\
\cline { 2 - 6 } & 300 & 200 & 100 & 60 & 30 & 6 & 600 & & 53.0 \\
\hline AAM & 101 & 67 & 30.5 & 14 & 9 & 1.5 & 162 & 191 & 35.0 \\
ADM & 125 & 91.5 & 53.5 & 36 & 21 & 5.5 & 209 & 144 & 50.0 \\
ADE & 100 & 69 & 32 & 15 & 10 & 2 & 175 & 187 & \\
\hline
\end{tabular}

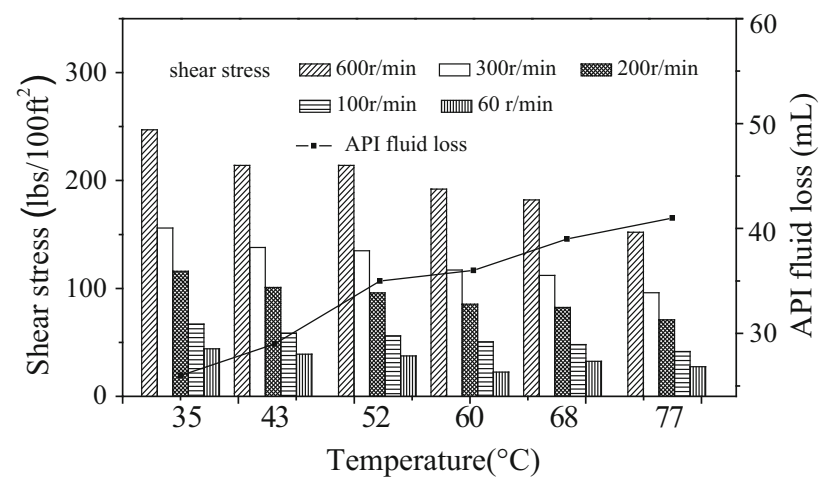

Fig. 4 Effects of temperature on shear stress and fluid loss of cement slurry containing $0.8 \%$ bwoc ADM

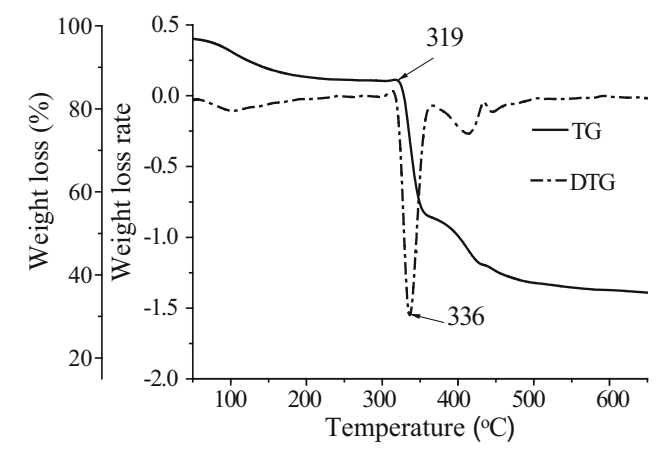

Fig. 5 TG-DTG curves of ADM

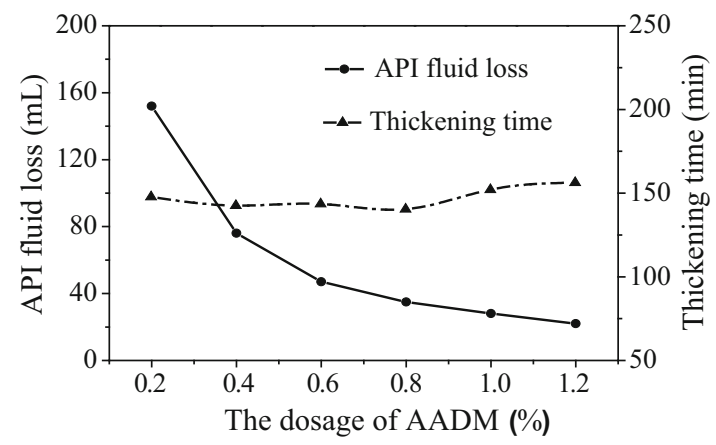

Fig. 6 Effects of ADM dosage on fluid loss and thickening time of cement slurry at $52{ }^{\circ} \mathrm{C}$

Figure 6 shows the effect of ADM dosage on shear stress and fluid loss of cement slurry. As observed, the fluid loss decreased with the increase of ADM dosage, resulting from the increase of shear stress in cement slurry. However, too high FLA dosage in cement slurry would cause the increase of cementing cost. Selecting an appropriate FLA dosage which was satisfactory in controlling fluid loss was required. In this study, dosage of $0.8 \%$ bwoc ADM was selected in view of the reason that change of fluid loss tends to be mild when dosage was more than $0.8 \%$. As observed in Fig. 6, the thickening time of cement slurry can be controlled to about $150 \mathrm{~min}$ when dosages of ADM were $0.2-1.2 \%$, showing a stable thickening property of 

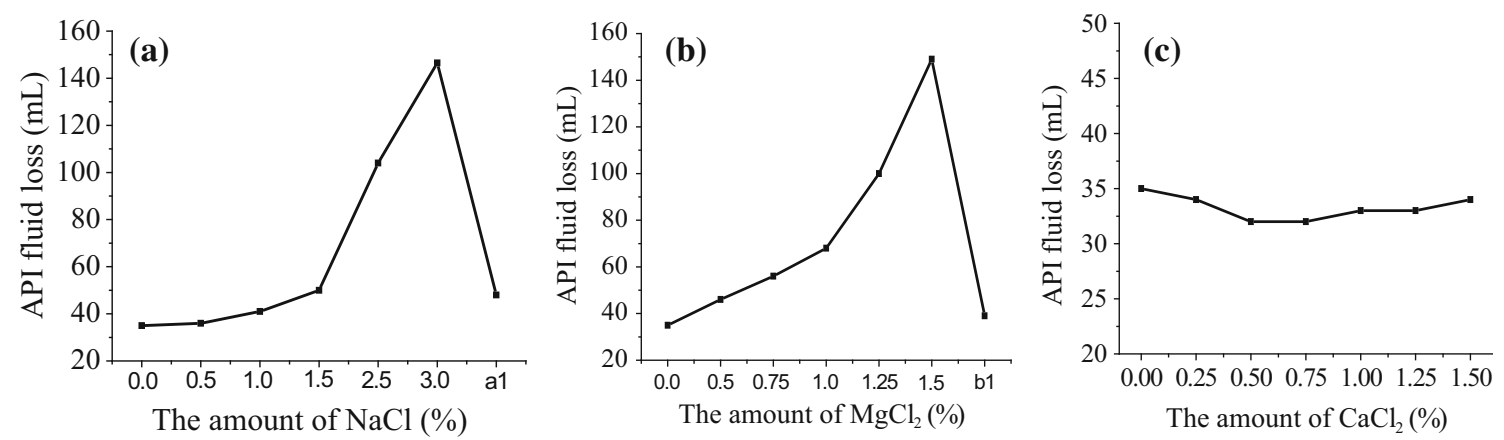

Fig. 7 Effects of $\mathrm{NaCl}(\mathbf{a}), \mathrm{MgCl}_{2}$ (b) and $\mathrm{CaCl}_{2}$ (c) on fluid loss of cement slurry containing $0.8 \%$ bwoc $\mathrm{ADM}$ at $52{ }^{\circ} \mathrm{C}$. a1, $3 \%$ $\mathrm{NaCl}+1.0 \%$ bwoc ADM; b1, $1.5 \% \mathrm{MgCl}_{2}+1.2 \%$ bwoc ADM

cement slurry which is necessary for keeping the pumping ability of cement slurry.

The salt resistance of cement slurry containing an ADM dosage of $0.8 \%$ bwoc was evaluated in the presence of three kinds of salts including $\mathrm{NaCl}, \mathrm{MgCl}_{2}$ and $\mathrm{CaCl}_{2}$ and the results are summarized in Fig. 7. As observed in Fig. 7a, fluid loss of cement slurry increased with increase of $\mathrm{NaCl}$ concentration, indicating the negative effects of $\mathrm{NaCl}$ on the fluid loss. In salt solution, the charged groups in biopolymer FLA were neutralized by the ions, which reduced the intramolecular charge repulsive force and resulted in the crispation of molecular chain (Zou et al. 2012), viscosity reduction and fluid loss. Fluid loss reached to $146.5 \mathrm{ml}$ when $\mathrm{NaCl}$ concentration was $3 \%$, which is difficult to meet the requirements of cementing job. FLA dosage was raised in the presence of $3 \% \mathrm{NaCl}$ to decrease fluid loss of cement slurry, and the result showed that a dosage of $1.0 \%$ bwoc ADM may reduce fluid loss to $48 \mathrm{ml}$ which can usually meet the cementing requirements, indicating excellent salt tolerance of ADM-containing cement slurry. Effects of $\mathrm{MgCl}_{2}$ on fluid loss of cement slurry showed a similar tendency to that of $\mathrm{NaCl}$. Whereas, fluid loss of cement slurry was hardly affected by $\mathrm{Ca}^{2+}$ when $\mathrm{Ca}^{2+}$ concentration was below $1.5 \%$, indicating strong $\mathrm{Ca}^{2+}$-resistance ability of cement slurry and possibly resulting from the combined action of several factors. On the one hand, $\mathrm{Ca}^{2+}$, like $\mathrm{Na}^{+}$and $\mathrm{Mg}^{2+}$, can neutralize the charges of FLA and negatively affect the fluid loss. One the other hand, $\mathrm{Ca}^{2+}$ has strong crosslink property, which would draw more FLA to the surface of cement particles and thus, enhance the blockage ability of cement slurry. In this study, two aspects of factors could counteract. Thus, $\mathrm{Ca}^{2+}$ with low concentration hardly affected the fluid loss of cement slurry.

\section{Conslusion}

In this study, three kinds of FLA were successfully prepared by polymerization of AMPS with AM, DMAM,
DEAM, respectively, and characterized by FTIR and NMR. FLA consisting of AMPS and DMAM (coded as ADM) showed the best water-retaining capacity and had a high temperature tolerance, resulting from strong rigidity of ADM molecule due to the existence of $-\mathrm{CH}_{3}$. Salttolerance experiments showed that resistance of cement slurry containing ADM to $\mathrm{Ca}^{2+}$ was stronger than that to $\mathrm{Mg}^{2+}$ and $\mathrm{Na}^{+}$.

Open Access This article is distributed under the terms of the Creative Commons Attribution License which permits any use, distribution, and reproduction in any medium, provided the original author(s) and the source are credited.

\section{References}

Amani M, Al-Jubouri M, Shadravan A (2012) Comparative study of using oil-based mud versus water-based mud in HPHT fields. Adv Pet Explor Dev 4:18-27

Clark PE (2010) Analysis of fluid loss data II: models for dynamic fluid loss. J Petrol Sci Eng 70:191-197

Dugonjić-Bilić F, Plank J (2011) Polyelectrolyte complexes from polyethylene imine/acetone formaldehyde sulfite polycondensates: a novel reagent for effective fluid loss control of oil well cement slurries. J Appl Polym Sci 121:1262-1275

Guo JT, Lu HC, Liu SQ, Jin JZ, Yu YJ (2012) The novel fluid loss additive HTF-200C for oil field cementing. Pet Explor Devt 39:385-390

Guo JT, Lu HC, Liu SQ, Jin JZ, Yu YJ, Yu QF (2013) A high temperature retarder HTR-300L applied in long cementing interval. Pet Exp Dev 40:656-660

Kelessidis VC, Papanicolaou C, Foscolos A (2009) Application of Greek lignite as an additive for controlling rheological and filtration properties of water-bentonite suspensions at high temperatures: a review. Int J Coal Geol 77:394-400

Kosynkin DV, Ceriotti G, Wilson KC, Lomeda JR, Scorsone JT, Patel AD, Friedheim JE, Tour JM (2012) Graphene oxide as a highperformance fluid-loss-control additive in water-based drilling fluids. ACS Appl Mater Interface 4:222-227

Ma C, Bu YH, Chen B (2014) Preparation and performance of a lignosulfonate-AMPS-itaconic acid graft copolymer as retarder for modified phosphoaluminate cement. Constr Build Mater 60:25-32

Peng B, Peng SP, Long B, Miao YJ, Guo WY (2010) Properties of high-temperature-resistant drilling fluids incorporating acrylamide/(acrylic acid)/(2-acrylamido-2-methyl-1-propane 
sulfonic acid) terpolymer and aluminum citrate as filtration control agents. J Vinyl Add Tech 16:84-89

Plank J, Brandl A, Zhai YA, Franke A (2006) Adsorption behavior and effective of poly ( $N, N$-dimethylacrylamide-co-Ca 2-acrylamido2-methyopropanesulfonate) as cement fluid loss additive in presence of acetone formaldehyde sulfite dispersant. J Appl Polym Sci 102:4341-4347

Plank J, Lummer NR, Dugonjić-Bilić F (2010) Competitive adsorption between an AMPS ${ }^{\circledR}$-based fluid loss polymer and Welan gum biopolymer in oil well cement. J Appl Polym Sci 116:2913-2919

Tao W, Jie Y, Sun ZS, Wang L, Wang J (2011) Solution and drilling fluid properties of water soluble AM-AA-SSS copolymers by inverse microemulsion. J Pet Sci Eng 78:334-337
Varaprasad K, Ravindra S, Reddy NN, Vimala K, Raju KM (2010) Design and development of temperature sensitive porous poly(NIPAAm-AMPS) hydrogels for drug release of doxorubicin-a cancer chemotherapy drug. J Appl Polym Sci 116:3593-3602

Yan LL, Wang CB, Xu B, Sun JS, Yue W, Yang ZX (2013) Preparation of a novel amphiphilic comb-like terpolymer as viscosifying additive in low-solid drilling fluid. Mater Lett 105:232-235

Zou CJ, Zhao PW, Ge J, Lei Y, Luo PY (2012) $\beta$-Cyclodextrin modified anionic and cationic acrylamide polymers for enhancing oil recovery. Carbohydr Polym 87:607-613 